\title{
Predicting hedgehog mortality risks on British roads using habitat suitability modelling
}

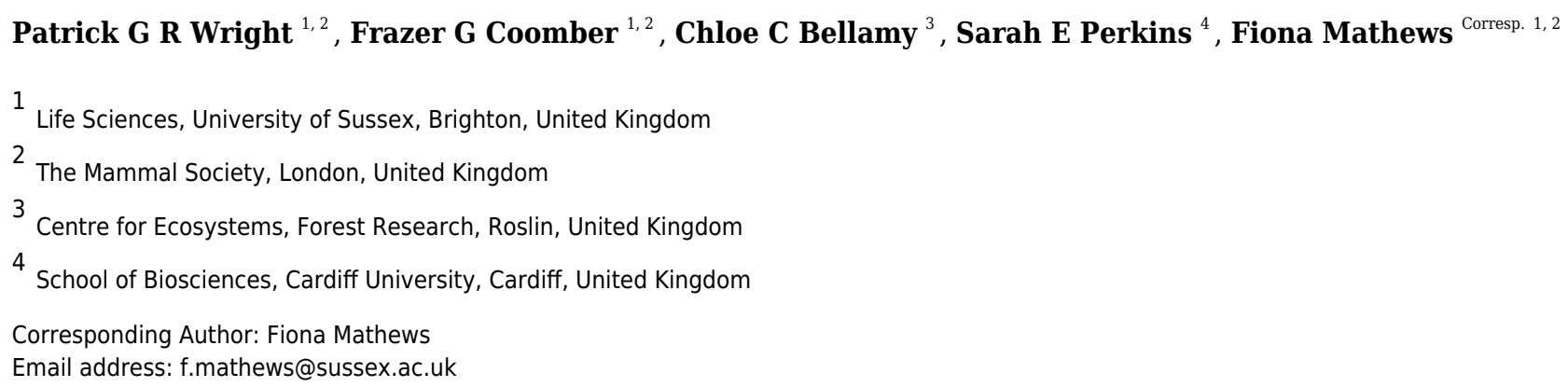

Road vehicle collisions are likely to be an important contributory factor in the decline of the European hedgehog (Erinaceus europaeus) in Britain. Here, a collaborative roadkill dataset collected from multiple projects across Britain was used to assess when, where and why hedgehog roadkill are more likely to occur. Seasonal trends were assessed using a Generalized Additive Model (GAM). There were few casualties in winter - the hibernation season for hedgehogs - with a gradual increase from February that reached a peak in July before declining thereafter. A sequential multi-level Habitat Suitability Modelling (HSM) framework was then used to identify areas showing a high probability of hedgehog roadkill occurrence throughout the entire British road network ( 400,000 km) based on multiscale environmental determinants. The HSM predicted that grassland and urban habitat coverage were important in predicting the probability of roadkill at a national scale. Probabilities peaked at approximately $50 \%$ urban cover at a $1 \mathrm{~km}$ scale and increased linearly with grassland cover (improved and rough grassland). Areas predicted to experience high probabilities of hedgehog roadkill occurrence were therefore in urban and suburban environments, i.e. where a mix of urban and grassland habitats occur. These areas covered $9 \%$ of the total area within the national British road network. Used alongside evidence on the persistence with which hedgehog roadkill are recorded in a given location over time, the HSM framework can help to identify priority areas for mitigation measures. 
1 Predicting hedgehog mortality risks on British roads using habitat suitability modelling

3

4 Dr. Patrick Graham Ross Wright ${ }^{1,2}$, Dr. Frazer Guy Coomber ${ }^{1,2}$, Dr. Chloe Bellamy ${ }^{3}$, Dr. Sarah

5 E. Perkins ${ }^{4} \&$ Prof. Fiona Mathews ${ }^{1,2}$

$6 \quad{ }^{1}$ Life Sciences, University of Sussex, Brighton, United Kingdom

$7 \quad 2$ The Mammal Society, London, United Kingdom

$8{ }^{3}$ Centre for Ecosystems, Forest Research, Roslin, United Kingdom

$9{ }^{4}$ School of Biosciences, Cardiff University, Cardiff, United Kingdom

11 Corresponding Author:

12 Fiona Mathews ${ }^{1,2}$

13 Email address: F.Mathews@sussex.ac.uk 
16 Abstract

17 Road vehicle collisions are likely to be an important contributory factor in the decline of the

18 European hedgehog (Erinaceus europaeus) in Britain. Here, a collaborative roadkill dataset

19 collected from multiple projects across Britain was used to assess when, where and why

20 hedgehog roadkill are more likely to occur. Seasonal trends were assessed using a Generalized

21 Additive Model (GAM). There were few casualties in winter - the hibernation season for

22 hedgehogs — with a gradual increase from February that reached a peak in July before declining

23 thereafter. A sequential multi-level Habitat Suitability Modelling (HSM) framework was then

24 used to identify areas showing a high probability of hedgehog roadkill occurrence throughout the

25 entire British road network $(\sim 400,000 \mathrm{~km})$ based on multi-scale environmental determinants.

26 The HSM predicted that grassland and urban habitat coverage were important in predicting the

27 probability of roadkill at a national scale. Probabilities peaked at approximately $50 \%$ urban cover

28 at a $1 \mathrm{~km}$ scale and increased linearly with grassland cover (improved and rough grassland).

29 Areas predicted to experience high probabilities of hedgehog roadkill occurrence were therefore

30 in urban and suburban environments, i.e. where a mix of urban and grassland habitats occur.

31 These areas covered $9 \%$ of the total area within the national British road network. Used

32 alongside evidence on the persistence with which hedgehog roadkill are recorded in a given

33 location over time, the HSM framework can help to identify priority areas for mitigation

34 measures. 


\section{Introduction}

Growing human populations and associated urbanisation have led to an expansion of road networks and traffic volumes globally. In Europe, an average of 70,000 km of roads are built every year, while in Britain, traffic on major roads has increased by $9.5 \%$ since 2000 and is expected to grow an estimated $17 \%-51 \%$ by 2050 (UK-Gov, 2018).

Road traffic has both direct and indirect impacts on wildlife (van der Ree et al., 2011; Rytwinski \& Fahrig, 2015; Bennett, 2017). These include the loss and fragmentation of habitat (Andrews, 1990; Eigenbrod, Hecnar, \& Fahrig, 2008; Ibisch et al., 2016), disturbance via elevated noise and pollution levels (Berthinussen \& Altringham, 2012), and direct mortality through wildlifevehicle collisions (WVCs), which can in turn drive population declines (Fahrig \& Rytwinski, 2009). Several studies have been undertaken to understand the threats posed by roads to wildlife, and to identify potential mitigation measures, although most published evidence is derived from regional case studies (van der Ree et al., 2011).

WVCs are known to occur for a wide range of mammal species (Barthelmess \& Brooks, 2010). Numerous studies have shown the negative impact of roadkill on populations of large carnivores, such as tigers (Panthera tigris altaica; Kerley et al., 2002), grizzly bears (Ursus arctos; Waller \& Servheen, 2005) and servals (Leptailurus serval; Williams et al., 2019). Collisions likely to pose a risk to human safety (e.g. with large mammals such as deer) are also a focus of research (Girardet, Conruyt-Rogeon, \& Foltête, 2015). The frequency of these collisions appears to be increasing, possibly owing to the global increases in traffic volume (e.g. Madsen, Strandgaard, \& Prang, 2002). Small mammal species ( $<1 \mathrm{~kg}$ in body mass), however, often go under recorded in roadkill surveys due to their lower detectability (Slater 2002; Ford \& Fahrig, 2007; Langen et al., 2007) and the fact that their carcases are rapidly scavenged (Slater, 2002; Barthelmess \& Brooks, 
59 2010; Schwartz et al., 2018). This hinders the ability to identify factors that are associated with

60 roadkill and the development of targeted and effective mitigation measures that aim to limit the

61 impact of roads on wildlife populations through either a modification of motorist behaviour

62 and/or the modification of animal behaviour (Glista, DeVault, \& DeWoody, 2009). These

63 measures are often species- or genus-specific, and vary in their forms (e.g. wildlife warning

64 signs, wildlife crossings, fencing, under- \& overpasses) and effectiveness in different situations

65 (Clevenger \& Waltho, 2000; Glista, DeVault, \& DeWoody, 2009; Rytwinski et al., 2016).

66 The likelihood of WVCs is often linked to local road characteristics and the surrounding

67 landscape (Neumann et al., 2012; Grilo et al., 2016; Santos et al, 2018). Habitat Suitability

68

69

Models (HSMs) can predict and examine the relationship between animal observation data and environmental variables through mathematical algorithms (Guisan \& Zimmermann, 2000; Elith $\&$ Leathwick, 2009). These models can be used to identify high quality habitat and derive information on the underlying environmental drivers (Phillips, Anderson, \& Schapire, 2006; Elith et al., 2011). Although HSMs are typically used to identify and predict species' habitat requirements (e.g. Razgour, Hanmer \& Jones, 2011; Croft, Chauvenet \& Smith, 2017), they have also been used previously to identify the environmental variables that explain and predict roadkill occurrence (e.g. Malo, Suarez \& Diez, 2004; Santos et al., 2013; Fabrizio et al., 2019). For example, Ha and Shilling (2018) successfully identified the impact of forest cover and road density on ungulates roadkill in Central California.

To create HSMs and other models to better understand WVC patterns, some prior, spatially explicit species information is required. Biological records, consisting of incidences where a species or other taxonomic group identification has been recorded alongside location, time and other metadata, can be collected via bespoke surveys. However, this approach is resource 
82 intensive and expensive. Biological records from citizen science studies, where volunteers

83 collect data as part of a scientific study and as ad hoc observations, represent a valuable source of

84 ecological data (Powney \& Isaac, 2015). Recent technological advancements, such as online

85 reporting and smart phone apps, have facilitated a huge growth in the adoption of this approach

86 in various fields (Silvertown, 2009; Pocock et al., 2015). Numerous citizen science approaches

87 have already been established for recording and surveying roadkill (e.g. Heigl \& Zaller, 2014;

88 Vercayier \& Herremans, 2015; Heigl et al., 2016); the resulting data have been shown to provide useful spatial information on roadkill clusters, despite varying slightly from data collected via comparable surveys run by trained observers (Periquet et al., 2018). However, biological records from citizen science projects or as ad hoc observations are typically unstructured and prone to biases and errors due to issues such as a lack of standardised survey protocols (Prendergast et al., 1993; Isaac et al., 2014). These biases can create noise in the data, which can hide or introduce false trends and increase uncertainty in analyses (Kamp et al., 2016). However, if records are carefully filtered to remove those with geographic uncertainty, and if sampling bias is effectively accounted for during analysis biological records represent a huge data resource (Kery et al., 2010; Hill, 2012; van Strien et al., 2013; Isaacs et al., 2014).

The aim of this study is to investigate the spatial and temporal distribution of European hedgehog (Erinaceus europaeus) roadkill records across the entire British road network and between different road types. The European hedgehog is widespread throughout most of Europe, but is thought to be in decline in many countries. In Britain, for example, population estimates

102 have reduced from 1.5 million individuals in 1995 to 522,000 in 2016 (Mathews et al., 2018).

103 The causes for the species' dramatic decline remain unclear, but factors including the 104 intensification of agriculture resulting in a loss of habitat and prey (Hof \& Bright, 2009), 
105 predation and competition with badgers (Pettett et al., 2018; Williams et al., 2018), and road

106 collisions (Huijser \& Bergers, 2000; Rondinini \& Doncaster, 2002) are likely to contribute. It has

107 been estimated that approximately 100,000 to 300,000 hedgehogs are killed every year on roads

108 in Britain (Roos, Johnston, \& Noble, 2012; Wembridge et al., 2016), Belgium (Holsbeek, Rodts,

$109 \&$ Muyldermans, 1999) and the Netherlands (Huijser, Bergers, \& De Vries, 1998). Yet, the

110 causal factors behind these large numbers of roadkill are still poorly understood.

111 We have analysed seasonal trends in hedgehog road casualties, and, using a multi-level HSM

112 framework, produced spatial predictions of the probability of hedgehog road casualties across

113 Britain, based on environmental variables. Furthermore, an analysis of temporal trends is used to

114 provide seasonal patterns of hedgehog roadkill risk and to highlight months when the majority of

115 roadkill are recorded. The outputs can inform targeted mitigation measures aiming at reducing

116 the impact of roads on the declining hedgehog population in Britain.

\section{Materials \& Methods}

\section{Hedgehog roadkill data}

119 Data on hedgehog roadkill were obtained from multiple citizen science projects in Britain (Big

120 Hedgehog Map, Mammal Mapper, Mammal Tracker, Mammals on Roads, Project Splatter and

121 Suffolk Wildlife Trust), National Biodiversity Network (NBN) gateway, and national and local

122 monitoring schemes (Supplementary 1). These records were collections of both transect

123 associated and opportunistic records, collected using a variety of recording methods, including:

124 online recording forms, smart phone apps and email submitted records. A total of 12,684

125 hedgehog roadkill records were collected from 1959 to 2018. 
126 Each record was subject to screening against inclusion criteria before being considered in the

127 models. Only confirmed roadkill records were used, for example live hedgehogs from projects

128 that did not specifically target roads were not included. Similarly, information on recorder effort

129 (e.g. transects) was not necessary and therefore not retained. Due to a very low number of

130 records before 2000, only records made between January 2000 and December 2017 were

131 included to coincide with the environmental data used. For each HSM level (1 km or $100 \mathrm{~m})$,

132 only records with a spatial precision equal or finer to the model resolution were retained, and

133 only single record per grid cell was used. Similarly, the seasonality model only included records

134 that had dates with information on at least month and year.

\section{Modelling hedgehog roadkill seasonality}

136 A Generalized Additive Model (GAM) was used to characterize the seasonal trends in hedgehog

137 roadkill throughout the year using the 'mgcv' package (Wood \& Wood, 2015) in the statistical

138 analysis software R (v. 3.4.3; R Core Team, 2018) and implemented in R Studio (v.1.1.456;

139 RStudio Team, 2018). The monthly number of hedgehog roadkill was modelled using a Poisson

140 family error distribution. Five candidate models were fitted using a cyclic cubic spline, with

141 twelve knots for the month variable. The best model was selected based on a generalized

142 likelihood ratio test. The autocorrelation function (ACF) and partial autocorrelation function

143 (pACF) were used to assess the residuals of all models. The first candidate model assumed that

144 all observations were independent. The next four candidate models included a correlation

145 argument for the month variable, within an extended mixed model framework of the GAM,

146 ranging from 1 to 4 , to account for temporal non-independence.

147 Modelling probability of hedgehog roadkill occurrence 
148 The probability of hedgehog roadkill occurrence on British roads was modelled using the

149 presence-only modelling software MaxEnt (Phillips, Anderson \& Schapire, 2006). MaxEnt

150 determines occurrence probabilities by using a set of explanatory variables together with species'

151 presence data and expresses the suitability of each grid cell as a function of the explanatory

152 variables within that grid cell (Phillips, Anderson \& Schapire, 2006). The filtered hedgehog

153 roadkill data were used as the presence data within all subsequent models (Figure 1). A suite of

154 candidate environmental explanatory variables was selected based on a priori expectations from

155 the literature that they influence the presence or behaviour of hedgehogs (e.g. Driezen et al.,

156 2007; Croft, Chauvenet, \& Smith, 2017). The source and resolution of the candidate explanatory

157 variables is provided in Table 1 and further information on their preparation can be found in

158 Supplementary 2.

159 The MaxEnt models were created and integrated across two levels using a multi-level HSM

160 framework developed by Bellamy et al. (In Review). This framework models species’

161 distributions at multiple geographic levels in turn, from coarsest to finest resolutions, whilst

162 including habitat suitability indices (HSI) from the preceding coarser resolution level as an

163 explanatory variable in models at a subsequent model level. This sequential approach reduces

164 predictor collinearity and enables a species' response to the local environment at lower levels to

165 vary according to higher level conditions (Bellamy et al., In Review). The modelling process for

166 hedgehog roadkill was set out as below:

1) A national-level model for the whole of Britain was constructed at a $1 \mathrm{~km}$ grid cell resolution. It focused on percentage cover of habitat variables, road density and climatic variables, which were measured at candidate resolutions of 1 and $3 \mathrm{~km}$ (Table 1 and Supplementary 2). 
171

172

173

174

175

176

177

178

179

180

181

182

183

184

185

186

187

188

189

190

191

192

193

2) Road-level models were constructed at a higher, $100 \mathrm{~m}$ grid cell resolution and covered all areas in Britain within $200 \mathrm{~m}$ of the road. Road types considered were based on the official and unofficial road type classifications of the Department of Transport (Department for Transport, 2002; refer to Supplementary 3 for full description and classifications of road types). Each individual road-level model was constructed according to the following road types:

a) Minor roads (minor roads and local roads)

b) B-roads

c) Major roads (A roads and motorways)

d) All roads combined.

The explanatory variables associated with the individual road-level models were primarily associated with distance to landscape features (e.g. distance from broadleaved woodland). All explanatory variables were measured at two candidate scales: 100 and $500 \mathrm{~m}$. Each variable was cropped within a $200 \mathrm{~m}$ buffer for each road type.

The national-level model was run first, and the HSI values for the probability of hedgehog roadkill occurrence were calculated. These values were then incorporated as an explanatory variable into the subsequent higher resolution road-level models, as described above, by disaggregating them to the resolution of road-level models. The optimal resolution for each variable was identified at each level by comparing the univariate MaxEnt model (default settings). The resolution which resulted in the model with the highest measure of training gain (interpreted as the likelihood of the presence points; Merow, Smith, and Silander , 2013), was retained for the final model. For each level, highly correlated variables were removed using the 'vifstep' stepwise function in the 'usdm' package (Naimi et al., 2014) based on a conservative 
194 VIF threshold of three (Zuur, Ieno, \& Elphick, 2010). The package 'ENMeval' (Muscarella et 195 al., 2014) was used to identify the optimal MaxEnt model settings. Combinations of feature 196 types were tested with the threshold features disabled to reduce overfitting (L, linear; H, hinge;

197 Q; quadratic; P, product): L, H, LQ, LQH and LQHP. The regularisation multiplier was varied in 198 steps of 0.5 , from 0.5 to 4 . These optimal settings were then used to produce model predictions. 199 All analyses were carried out using R (v. 3.4.3; R Core Team, 2018) in R Studio (v.1.1.456; 200 RStudio Team, 2018) and using code adpated from Bellamy et al. (In Review).

201 The HSIs from each HSM were used to classify grid cells with the highest probability of 202 hedgehog roadkill occurrence. The predicted HSI values were partitioned into a binary response 203 (high and low probability of hedgehog roadkill occurrence) using the Maximum Training 204 Sensitivity and Specificity (MTSS) occupancy rule (Liu, White, \& Newell, 2013).

205 In order to compare hedgehog roadkill probabilities between the different road types, the mean 206 HSI value of major roads, B-road and minor road-level models were extracted directly from the 207 'all roads' model. A high probability of hedgehog roadkill occurrence ratio was also calculated 208 to consider differences in total road type length. To take into account differences in the 209 availability of different road types, a ratio of the probability of occurrence relative to the length 210 of each road type was computed. The ratio was calculated as the number of $100 \mathrm{~m}^{2}$ grid cells 211 classed as high probability of roadkill occurrence divided by the number of grid cells classified 212 as having a low probability of roadkill occurrence (based on binary model outputs).

213 To control for possible bias in the hedgehog roadkill records towards locations that were heavily 214 observed, pseudo-absence points (background points) were used for the HSMs based on the 215 combined roadkill records of seven other mammal species. The species used (Vulpes vulpes, 216 Neovison vison, Mustela erminea, Mustela nivalis, Meles meles, Lutra lutra, and Capreolus 
217 capreolus) all shared a similar national distribution and are frequently recorded as roadkill.

218 These records were from the same time period and underwent the same inclusion criteria as the

219 hedgehog dataset. For the road-level models, subsets were created by including only records that

220 were within the $200 \mathrm{~m}$ road buffers. HSMs were also run using 10,000 (national model) and

2212,500 (road models) random pseudo-absence points. The degrees of similarity between the

222 roadkill and random pseudo-absence HSMs were assessed using Schoener's index. HSM

223 performance was judged using the Area Under Curve (AUC) test statistic, with 1 being perfect

224 predictions and 0.5 representing a model that does not predict better than random.

225 To test for variations between the observed hedgehog roadkill records and the locations predicted

226 to have a high probability of occurrence, three maps were also produced:

227

228

229

230

231

232

233

234

235

236
1) The inter-annual persistence of observed roadkill was calculated based on the number of years that at least one hedgehog roadkill per year was recorded in each $10 \mathrm{~km}$ British National Grid cell.

2) Kernel density at a $10 \mathrm{~km}$ resolution of the number of roadkill presence records used for the national-level model.

3) Kernel density at a $10 \mathrm{~km}$ resolution of grid cells classified as having a high probability of hedgehog roadkill occurrence based on the 'all roads' HSM binary results.

The correlation between all three outputs was then assessed using pairwise Pearson's correlation between all three outputs. 


\section{Results}

238 After the inclusion criteria were applied to all the hedgehog roadkill data, a total of 6,004 records

239 were available for all subsequent HSMs (Figure 1) and 3,777 for the seasonal analysis. Records

240 were spread throughout Britain and displayed distinct areas of high and low recording (Figure 1).

241 The seasonal analysis used the GAM model with a correlation argument of two, this being the

242 best candidate model based on the Generalised Likelihood Ratio Test. The inclusion of a

243 correlation argument took into account the temporal correlations between the monthly roadkill

244 records. The GAM indicated clear seasonal variations in the relationship between the months of

245 the year and the number of hedgehog roadkill recorded $\left(\mathrm{F}_{9,24}=124.98, \mathrm{p}<0.001\right)$. The

246 smoothing function indicated that roadkill was at its lowest in winter, gradually increased to a

247 peak in July, then subsequently decreased (Figure 2).

248 All models were adequate, based on the AUC scores, but some performed better than others did.

249 The national, minor, and all road level models performed well with AUC scores higher than

250 0.70, while the major roads and B-road models performed less well (AUC $\leq 0.6)$. High niche

251 overlap between models using roadkill and random pseudo-absence background data was

252 identified with all Schoener's D statistics being $>0.85$ (Table 2).

253 The shape and strength of the species-environment relationships varied between HSMs. The

254 output response curves and permutation importance values varied between the different model

255 levels and the different pseudo-absence data used, roadkill or random (Figure 3; Supplementary

2564 - 18). However, certain variables, such as those associated with urban cover, buildings and

257 grasslands, had a consistent importance throughout all models. 
258 The probability of hedgehog roadkill occurrence in the national-level model using roadkill

259 pseudo-absences was characterised by medium to high urban cover (permutation importance: 68

$260 \%$ at a $1 \mathrm{~km}$ scale), with probability of occurrence reaching a peak at approximately $50 \%$ urban

261 cover (Figure 3). Grassland cover was also important (permutation importance: 10\% at a $1 \mathrm{~km}$

262 scale for improved grassland and a $3 \mathrm{~km}$ scale for rough grassland) with the probability of

263 roadkill occurrence increasing with the amount of improved and rough grassland coverage

264 (Figure 3A; Figure 3C - Figure 3F). Similar results were also found with the national-level model

265 that used random pseudo-absences (Supplementary 4 \& 7).

266 The road-level model with roadkill pseudo-absences identified distance from major roads, B

267 roads and buildings at a $100 \mathrm{~m}$ scale as important predictors, alongside distance from rough

268 grassland at a $500 \mathrm{~m}$ scale (Figure 3B; Figure 3G - Figure 3J). While the outputs of the different

269 road-level models showed high overlap (Table 2), the permutation importance of the national-

270 level HSI varied considerably according to which background dataset was used (roadkill or

271 random). The HSI variables from the national-level model had a high importance $(\sim 50 \%)$ when

272 using random points and very low importance $(<5 \%)$ when using the pseudo-absence roadkill

273 data (Figure 3 and Supplementary 5).

274 The mean HSI value extracted from the road-level model containing all roads (100 m resolution)

275 indicated a higher probability of hedgehog roadkill occurrence on major roads $(0.48)$ compared

276 to minor roads $(0.35)$ and B-roads (0.28). Major roads also had a higher probability of roadkill

277 occurrence ratio (0.52) than that of B-roads (0.38) and minor roads $(0.11)$.

278 The binary response (high and low probability of a roadkill occurence) using the MTSS

279 identified a total of $9 \%$ of the $100 \mathrm{~m}^{2}$ grid cells from the road network, based on the 'all roads' 
280 level model, as having a high probability of hedgehog roadkill occurrence. These areas were

281 mainly in central Britain, southern Wales, the outskirts of London, and southern Scotland (Figure

282 4). The outputs also regularly identified large areas of small towns, while only the edges of large

283 cities had a high probability of roadkill occurrence (Figure 4).

284 High levels of correlation were identified between the persistence of records over time and the

285 kernel density of roadkill records (at $10 \mathrm{~km}$ resolution) $(\mathrm{r}=0.93$; Figure 5). However, the kernel

286 density of $100 \mathrm{~m}$ resolution grid cells predicted to have a high probability of roadkill occurrence

287 showed a lower correlation with both the persistence and presence data $(\mathrm{r} \leq 0.55$; Figure 5$)$. The

288 HSM identified regions of high probability of roadkill that were not identified from the presence

289 records alone, such as the Central Belt (southern Scotland). It also helped identify that areas with

290 a high number of records do not necessarily identify areas with a high probability of hedgehog

291 roadkill occurrence on a national scale, e.g. eastern England (Figure 5).

\section{Discussion}

293 Vehicle collisions are a major threat contributing to the decline of hedgehogs in Britain. In this

294 study, roadkill data were analysed using GAMs and multi-level HSMs to understand seasonal

295 trends, assess the influence of landscape variables and to identify areas with a high probability of

296 roadkill occurrence. These analyses were conducted throughout the entire British road network

$297(\sim 400,000 \mathrm{~km})$ at a national scale but using a local resolution $(100 \mathrm{~m})$.

298 The seasonal trends in hedgehog roadkill, with low probability in the winter and higher

299 probability in summer, aligns with expectations from hedgehog biology and behaviour:

300 hedgehogs in Britain typically hibernate between October/November to March/April (Reeve,

301 1994), whereas they are active largely between March and October in England (Reeve, 1981). 
302 The single peak of roadkill in July is similar to the findings of Canova and Balestrieri (2019) and

303 Orlowski and Nowak (2006), who found peak distributions of hedgehog roadkill in July and

304 August in Northern Italy and Poland respectively, and suggests that roadkill is likely to be linked

305 with breeding, rather than night length. The results could indicate that most British hedgehogs

306 have a single litter, as roadkill peaks are expected to coincide with population peaks and with the

307 dispersal of vulnerable juvenile hedgehogs from their natal area. Mitigation measures are

308 therefore likely to be most successful if they are implemented during these months when

309 hedgehogs are more vulnerable.

310 Hedgehog roadkill probability is linked to a combination of environmental and abiotic variables.

311 The following habitat variables were important predictors of hedgehog roadkill: the extent of

312 improved grassland; the extent of rough grassland; urban land use; and road density

313 (combination of distance from major and B roads). This aligns with studies of other wildlife that

314 suggest that collision probability increases where there is a combination of favourable habitat

315 and human dominated areas (Neumann et al., 2012; Santos et al., 2018).

316 The findings presented here cannot distinguish whether the probability of hedgehog casualties is

317 determined by habitat per se, by high hedgehog densities associated with these habitats, or a

318 combination of the two. The recent population review of British mammals (Mathews et al.,

319 2018) found that unimproved (rough) grassland and arable habitats made substantial

320 contributions to the total population estimate, with over $55 \%$ of the total estimated British

321 hedgehog population being associated with these two habitats. Croft, Chauvenet \& Smith (2017)

322 also predicted that hedgehog abundance was highest in improved grassland and arable habitats,

323 supporting this study's findings that arable, improved, and rough grassland, were listed in the top

324 four influential habitats (Supplementary 9). Croft et al. (2017) also reported very high habitat 
325 suitability indices for urban habitats, followed equally by suburban and broadleaved woodlands.

326 Almost $40 \%$ of the estimated population of hedgehogs in Britain was derived from broadleaved

327 woodland habitat (Mathews et al., 2018). However, it is not a notably influential factor in the

328 current hedgehog roadkill models. Recorder efficiency may be reduced in roads that pass through

329 woodlands as fallen leaves, shade, dappled light, and increased scavenging rates may reduce the

330 visibility of hedgehog roadkill. This study's finding of increased probability of hedgehog

331 roadkill occurrence on major roads corresponds with earlier research (Bright, George, \&

332 Balmforth, 2005).

333 The models have predicted areas of the British road network that are likely to have high

334 probability of hedgehog roadkill. Both the national and road-level models identified central

335 Britain as being a large area where hedgehog collisions are highly probable. This is the region

336 where there is the most persistence (i.e. inter-annual records) of roadkill records since 2000.

337 Urbanisation levels are also known to be a significant barrier for the range expansion of both

338 polecats (Mustela putorius) and pine martens (Martes martes) in this region (Vincent Wildlife

339 Trust, 2019). At a local scale the prediction maps suggest that elevated roadkill probability

340 occurs throughout small villages and towns, but is restricted to the suburban areas of larger

341 cities, owing to the lack of grassland in the central parts of large cities. Similarly, Orlowski and

342 Nowak (2006) in a small scale and largely rural study found that most roadkill occurred inside

343 villages.

344 The identification of regions with elevated probability of hedgehog roadkill occurrence provides

345 the opportunity to target mitigation and to test its effectiveness. The finding that only $9 \%$ of the

346 whole road network is identified as presenting a high probability of hedgehog roadkill provides

347 an initial focus for interventions, and we recommend wider-scale collection of data at high 
348 spatial resolution could help improve the models further. For example, at a national scale,

349 mitigation may be best targeted on Central Britain, as this includes many areas of high

350 probability of occurrence and with repeated records across multiple years. At a local scale, high

351 resolution models of roads can help identify those roads - possibly even locations within roads

352 - where mitigation measures may be the most effective (See supplementary 19 for Chesterfield

353 case study). It is notable that in this example nearly all areas that have multiple reports of

354 hedgehog roadkills across time coincide with the areas predicted to have a high probability of

355 roadkill.

356 Mitigation measures have been shown to be a cost effective tool in reducing the number and

357 effect of roadkills, e.g. with large ungulates in the United States and Canada (Huijser et al.,

358 2009). Many measures will work best when engaging with communities and influencing

359 national policies, through increased awareness and effectively implemented management plans

360 (Dickman, 2010). There are a variety of mitigation options that could be used to lower the

361 probability of hedgehog roadkill (Glista, DeVault \& DeWoody, 2009; Rytwinski et al., 2016).

362 Although hedgehog roadkill probability was positively associated with good habitat, it is

363 important to ensure that mitigation measures ensure safe crossing of roads rather than dissuading

364 hedgehogs to use such habitats. Road signs and speed reductions can be used to alert drivers

365 when approaching areas of high risk. Although this type of intervention does not affect all

366 species equally (Dique et al., 2003), they were found to decrease overall roadkill (including

367 echidna, a species with similar ecological traits to the European hedgehog) in Tasmania by $\sim 50 \%$

368 through a speed reduction of 20\% (Hobday \& Minstrelle, 2008). Fencing could help channel

369 hedgehog movement away from roads, although other structures that improve connectivity by

370 providing safe corridors across roads, such as overbridges, underpasses and culverts, may be 
371 preferred (e.g. van Vuurde \& van der Grift, 2005). It must be emphasised that the effectiveness

372 of many of these structural mitigation measures still remains unclear (Rytwinski et al., 2016) and

373 are largely determined by a few successful examples (Glista, DeVault \& DeWoody, 2009). The

374 continued recording of roadkill at high spatial resolution, before and after the implementation of

375 mitigation measures, can provide important evidence on the effectiveness of the measures taken.

376 It is vital that future monitoring is conducted at a high spatial resolution: a large number of data

377 points supplied to this project had to be discarded prior to analysis based on precision filtering (>

$37850 \%$ of records of the records used for the national model were discarded for the 'all roads'

379 model and $>85 \%$ of records were discarded for the major and B-road models). This may in turn,

380 result in the low performance of models, low AUC values, as observed with the B-road and

381 major road models. Moreover, citizen science records should be supplemented by data from

382 dedicated surveys, so that true absence data, rather than pseudo-absence, can be used to construct

383 models (e.g. Brotons et al., 2004; Fiedler et al., 2018). The HSMs could also be refined in the

384 future by separating major trunk roads from motorways, and by incorporating potentially

385 important variables such as traffic speed (these data are not currently available at a national level

386 for Britain).

387 During the model selection process various candidate models were run with different spatial

388 scales and pseudo-absence (roadkill and random) points and each provided slightly different

389 variable importance and outcomes (Supplementary 5-18). Grilo et al. (2016) also found the

390 relative importance of variables in the model outputs were not materially altered by changes in

391 sample units and spatial scales. However, the use of different types of background data did affect

392 the importance of certain variables. The national-level HSI, for example, had a high permutation importance $(>50 \%)$ when using random pseudo-absence data and a low importance $(<10 \%)$ 
394 when using roadkill pseudo-absence data. The random pseudo-absence data were spread

395 throughout the width of the road buffer and were consequently further from roads than the

396 roadkill pseudo-absence data. This could have adjusted the effect of distance from roads on

397 hedgehog roadkill and subsequently help better target the effect of specific roads. Future

398 monitoring programmes can be used to ground truth the model results by supplying an

399 independent training dataset against which the model predictions and independent observations

400 can be compared.

401 The use of different types of background data helps to avoid potential recorder bias generating

402 erroneous conclusions. For example, it is uncertain whether roadkills were most recorded in

403 areas with a high probability of hedgehog roadkill occurrence, or whether certain individuals or

404 local citizen science projects, gathering numerous records at a local scale generate 'clusters' of

405 records (Isaac \& Pocock, 2015). Therefore, the use of random pseudo-absence data was expected

406 to be somewhat biased towards heavily sampled areas, while the roadkill pseudo-absence data

407 would spread predictions to unsampled areas where conditions are similar to sampled areas

408 (Phillips et al., 2009). The low correlation found between the density of roadkill records and

409 roadkill predictions indicates that predictions were not exclusive to highly sampled areas and,

410 therefore, accounted for recorder effort.

\section{Conclusions}

412 This work has shown how the collection of roadkill data can provide large datasets that can be 413 used to understand the seasonal variations, environmental determinants, and spatial distribution

414 of hedgehog roadkill. Our findings suggest that drivers should be most vigilant for hedgehogs in

415 July on roads surrounded by a mix of urban and grassland cover. Areas with high probability of

416 roadkill occurrence and persistent reports of roadkill were identified across the entire road 
417 network at a spatial resolution fine enough to contribute to local planning and mitigation. Using

418 this information to target roadkill mitigation efforts should improve our ability to alleviate the

419 impact of projected increases in road cover, traffic levels and urbanisation on the size and

420 potential viability of already declining local and national hedgehog populations in Britain.

\section{Acknowledgments}

422 We are extremely grateful to the teams involved in the setup of Big Hedgehog Map, Mammal

423

424

425

426

427

428

429

430

431

432

433

434

435

436

437

438

439

440

441

442

443

444

445

446

447

448

Mapper, Mammal Tracker, Mammals on Roads, Project Splatter and Suffolk Wildlife Trust and the citizen scientists involved in the collection of hedgehog roadkill records over the years. We would also like to thank Emily Wilson and Emily Marnham for collating the roadkill data for this project.

\section{References}

Andrews, A. (1990). Fragmentation of habitat by roads and utility corridors: a review. Australian Zoologist, 26(3-4): 130-141.

Barthelmess, E. L. \& Brooks, M. S. (2010). The influence of body-size and diet on road-kill trends in mammals. Biodiversity and Conservation, 19(6): 1611-1629.

Bellamy, C. (In Review). A sequential multi-level framework to improve habitat suitability modelling.

Bennett, V. J. (2017). Effects of road density and pattern on the conservation of species and biodiversity. Current Landscape Ecology Reports, 2(1): 1-11.

Berthinussen, A., \& Altringham, J. (2012). The effect of a major road on bat activity and diversity. Journal of Applied Ecology, 49(1): 82-89.

Bright, P., George, L., \& Balmforth, Z. (2005). Mammals on Roads. Development and testing the use of road counts to monitor abundance. People's Trust for Endangered Species/Joint Nature Conservation Committee: Peterborough.

Brotons, L., Thuiller, W., Araújo, M. B. \& Hirzel, H. (2004). Presence-absence versus presenceonly modelling methods for predicting bird habitat suitability. Ecography, 27: 437-448.

Canova, L., \& Balestrieri, A. (2019). Long-term monitoring by roadkill counts of mammal populations living in intensively cultivated landscapes. Biodiversity and Conservation, 28(1): 97-113.

Clevenger, A. P., \& Waltho, N. (2000). Factors influencing the effectiveness of wildlife underpasses in Banff National Park, Alberta, Canada. Conservation Biology, 14(1): 4756. 
449

450

451

452

453

454

455

456

457

458

459

460

461

462

463

464

465

466

467

468

469

470

471

472

473

474

475

476

477

478

479

480

481

482

483

484

485

486

487

488

489

490

491

492

493

Croft, S., Chauvenet, A. L., \& Smith, G. C. (2017). A systematic approach to estimate the distribution and total abundance of British mammals. PLoS One, 12(6): e0176339. data.gov.uk. (2019). GB Road Traffic Counts. Retrieved from https://data.gov.uk/dataset/208c0e7b-353f-4e2d-8b7a-1a7118467acc/gb-road-trafficcounts

Department for Transport, (2002). Guidance on Road Classification and the Primary Route Network. Report by the Department for transport

Dickman, A. J. (2010). Complexities of conflict: the importance of considering social factors for effectively resolving human-wildlife conflict. Animal Conservation, 13(5): 458-466.

Dique, D. S., Thompson, J., Preece, H. J., Penfold, G. C., de Villiers, D. L., \& Leslie, R. S. (2003). Koala mortality on roads in south-east Queensland: the koala speed-zone trial. Wildlife Research, 30: 419-426.

Driezen, K., Adriaensen, F., Rondinini, C., Doncaster, C. P., \& Matthysen, E. (2007). Evaluating least-cost model predictions with empirical dispersal data: a case-study using radiotracking data of hedgehogs (Erinaceus europaeus). Ecological Modelling, 209(2-4): 314-322.

Eigenbrod, F., Hecnar, S. J., \& Fahrig, L. (2008). Accessible habitat: an improved measure of the effects of habitat loss and roads on wildlife populations. Landscape Ecology, 23(2): 159168.

Elith, J., \& Leathwick, J. R. (2009). Species distribution models: ecological explanation and prediction across space and time. Annual Review of Ecology, Evolution, and Systematics, 40: 677-697.

Elith, J., Phillips, S. J., Hastie, T., Dudík, M., Chee, Y. E., \& Yates, C. J. (2011). A statistical explanation of MaxEnt for ecologists. Diversity and Distributions, 17(1): 43-57.

Fabrizio, M., Di Febbraro, M., D’Amico, M., Frate, L., Roscioni, F. \& Loy, A. (2019). Habitat suitability vs landscape connectivity determining roadkill risk at a regional scale: a case study on European badger (Meles meles). European Journal of Wildlife Research, 65(7): 10.

Fahrig, L., \& Rytwinski, T. (2009). Effects of roads on animal abundance: an empirical review and synthesis. Ecology and Society, 14(1): 21.

Fick, S.E. \& R.J. Hijmans, (2017). Worldclim 2: New 1-km spatial resolution climate surfaces for global land areas. International Journal of Climatology.

Fiedler, P. C., Redfern, J. V., Forney, K. A., Palacios, D. M., Sheredy, C., Rasmussen, K., García-Godos, I., Santillán, L., Tetley, M. J., Félix, F. \& Ballance, L. T. (2018). prediction of large whale distributions: a comparison of presence-absence and presenceonly modeling techniques. Frontiers in Marine Science, 5: 419.

Ford, A. T. \& Fahrig, L. (2007). Diet and body size of North American mammal road mortalities. Transportation Research Part D, 12: 498-505.

Gallego, F. J. (2010). A population density grid of the European Union. Population and Environment, 31: 460-473.

Girardet, X., Conruyt-Rogeon, G., \& Foltête, J. C. (2015). Does regional landscape connectivity influence the location of roe deer roadkill hotspots? European Journal of Wildlife Research, 61(5): 731-742.

Glista, D. J., DeVault, T. L., \& DeWoody, J. A. (2009). A review of mitigation measures for reducing wildlife mortality on roadways. Landscape and Urban Planning, 91(1): 1-7.

Peer) reviewing PDF | (2019:06:38456:2:0:NEW 24 Oct 2019) 
494

495

496

497

498

499

500

501

502

503

504

505

506

507

508

509

510

511

512

513

514

515

516

517

518

519

520

521

522

523

524

525

526

527

528

529

530

531

532

533

534

535

536

537

538

539

Grilo, C., de Resende Cardoso, T., Solar, R., \& Bager, A. (2016). Do the size and shape of spatial units jeopardize the road mortality-risk factors estimates? Natureza \& Conservação, 14(1): 8-13.

Guisan, A., \& Zimmermann, N. E. (2000). Predictive habitat distribution models in ecology. Ecological Modelling, 135(2): 147-186.

Ha, H., \& Shilling, F. (2018). Modelling potential wildlife-vehicle collisions (WVC) locations using environmental factors and human population density: a case-study from 3 state highways in Central California. Ecological Informatics, 43: 212-221.

Hill, M. O. (2012). Local frequency as a key to interpreting species occurrence data when recording effort is not known. Methods in Ecology \& Evolution, 3(1): 195-205.

Heigl, F., Stretz, C., Steiner, W., Suppan, F., Bauer, T., Laaha, G. \& Zaller, J. (2016). Comparing road-kill datasets from hunters and citizen scientists in a landscape context. Remote Sensing, 8(10): 832.

Heigl, F. \& Zaller, J. G. (2014). Using a citizen science approach in higher education: a case study reporting roadkills in austria. Human Computation, 1(2):165-175.

Hof, A. R., \& Bright, P. W. (2009). The value of green-spaces in built-up areas for western hedgehogs. Lutra, 52(2): 69-82.

Holsbeek, L., Rodts, J., \& Muyldermans, S. (1999). Hedgehog and other animal traffic victims in Belgium: results of a countrywide survey. Lutra, 42: 111-119.

Huijser, M. P., Bergers, P., \& De Vries, H. (1998). Hedgehog traffic victims: how to quantify effects on the population level and the prospects for mitigation. Paper presented at the International Conference on Wildlife Ecology and Transportation (ICOWET 1998) Florida Department of TransportationUS Department of TransportationUS Forest Service Defenders of Wildlife.

Huijser, M. P., \& Bergers, P. J. (2000). The effect of roads and traffic on hedgehog (Erinaceus europaeus) populations. Biological Conservation, 95(1): 111-116.

Ibisch, P. L., Hoffman, M. T., Kreft, S., Pe'er, G., Kati, V., Biber-Freudenberger, L., Dellasala, D. A., Vale, M. M., Hobson, P. R. \& Selva, N. (2016). A global map of roadless areas and their conservation status. Science, 354(6318): 1423-1427.

Isaac, N. J., \& Pocock, M. J. (2015). Bias and information in biological records. Biological Journal of the Linnean Society, 115(3): 522-531.

Isaac, N. J. B., van Strien, A. J., August, T. A., de Zeeuw, M. P., Roy, D. B. \& Anderson, B. (2014). Statistics for citizen science: extracting signals of change from noisy ecological data. Methods in Ecology and Evolution, 5(10): 1052-1060.

Jackson, D. (2006). The breeding biology of introduced hedgehogs (Erinaceus europaeus) on a Scottish Island: lessons for population control and bird conservation. Journal of Zoology, 268(3): 303-314.

Kamp, J., Oppel, S., Heldbjerg, H., Nyegaard, T., Donald, P. F. \& Schröder, B. (2016). Unstructured citizen science data fail to detect long-term population declines of common birds in Denmark. Diversity and Distributions, 22(10): 1024-1035.

Kerley, L. L., Goodrich, J. M., Miquelle, D. G., Smirnov, E. N., Quigley, H. B., \& Hornocker, M. G. (2002). Effects of roads and human disturbance on Amur tigers. Conservation Biology, 16(1): 97-108.

Kery, M., Royle, J. A., Schmid, H., Schaub, M., Volet, B., Hafliger, G. \& Zbinden, N. (2010). Site-occupancy distribution modeling to correct population-trend estimates derived from opportunistic observations. Conservation Biology, 24(5): 1388-97. 
540

541

542

543

544

545

546

547

548

549

550

551

552

553

554

555

556

557

558

559

560

561

562

563

564

565

566

567

568

569

570

571

572

573

574

575

576

577

578

579

580

581

582

583

584

Langen, T. A., Machniak, A., Crowe, E. K., Mangan, C., Marker, D. F., Liddle, N. \& Roden, B. (2007). Methodologies for surveying herptofauna mortality on rural highways. Journal of Wildlife Management, 71(4): 1361-1368.

Liu, C., White, M., \& Newell, G. (2013). Selecting thresholds for the prediction of species occurrence with presence-only data. Journal of Biogeography, 40(4): 778-789.

Madsen, A. B., Strandgaard, H., \& Prang, A. (2002). Factors causing traffic killings of roe deer Capreolus capreolus in Denmark. Wildlife Biology, 8(1): 55-62.

Malo, J. E., Suarez, F. \& Diez, A. (2004). Can we mitigate animal-vehicle accidents using predictive models. Journal of Applied Ecology, 41(4): 701-710.

Mathews, F., Kubasiewicz, L., Gurnell, J., Harrower, C., McDonald, R., \& Shore, R. (2018). A Review of the Population and Conservation Status of British Mammals. A report by the Mammal Society under contract to Natural England, Natural Resources Wales and Scottish Natural Heritage. Retrieved from Peterborough: http://nora.nerc.ac.uk/id/eprint/520584/1/N520584CR.pdf

Merow, C., Smith, M. J., \& Silander Jr, J. A. (2013). A practical guide to MaxEnt for modeling species' distributions: what it does, and why inputs and settings matter. Ecography, 36(10): 1058-1069.

Morton, D., Rowland, C., Wood, C., Meek, L., Marston, C., Smith, G., . . Simpson, I. C. (2011). Final Report for LCM2007 - the new UK land cover map. Retrieved from Countryside Survey Technical Report No 11/07 NERC/Centre for Ecology \& Hydrology 112pp. (CEH Project Number: C03259)

Muscarella, R., Galante, P. J., Soley-Guardia, M., Boria, R. A., Kass, J. M., Uriarte, M., \& Anderson, R. P. (2014). ENM eval: an R package for conducting spatially independent evaluations and estimating optimal model complexity for Maxent ecological niche models. Methods in Ecology and Evolution, 5(11): 1198-1205.

Naimi, B., Hamm, N. A., Groen, T. A., Skidmore, A. K., \& Toxopeus, A. G. (2014). Where is positional uncertainty a problem for species distribution modelling? Ecography, 37(2): 191-203.

Neumann, W., Ericsson, G., Dettki, H., Bunnefeld, N., Keuler, N. S., Helmers, D. P., \& Radeloff, V. C. (2012). Difference in spatiotemporal patterns of wildlife road-crossings and wildlife-vehicle collisions. Biological Conservation, 145(1): 70-78.

Orlowski, G., \& Nowak, L. (2006). Factors influencing mammal roadkills in the agricultural landscape of south-western Poland. Polish Journal of Ecology, 54(2): 283-294.

OS MasterMap Topography Layer (2019). EDINA Digimap Ordnance Survey Service. Retrieved from: http://digimap.edina.ac.uk/

OS Open Roads (2019). EDINA Digimap Ordnance Survey Service. Retrieved from: http://digimap.edina.ac.uk/

Périquet, S., Roxburgh, L., le Roux, A. \& Collinson, W. J.(2018). Testing the value of citizen science for roadkill studies: a case study from south africa. Frontiers in Ecology and Evolution, 6(15):1-18.

Pettett, C. E., Johnson, P. J., Moorhouse, T. P., \& Macdonald, D. W. (2018). National predictors of hedgehog Erinaceus europaeus distribution and decline in Britain. Mammal Review, 48(1): $1-6$.

Phillips, S., Anderson, R. P., \& Schapire, R. (2006). Maximum entropy modeling of species geographic distributions. Ecological Modeling, 190(3-4), 231-259. 
585

586

587

588

589

590

591

592

593

594

595

596

597

598

599

600

601

602

603

604

605

606

607

608

609

610

611

612

613

614

615

616

617

618

619

620

621

622

623

624

625

626

627

628
Phillips, S. J., Dudík, M., Elith, J., Graham, C. H., Lehmann, A., Leathwick, J., \& Ferrier, S. (2009). Sample selection bias and presence-only distribution models: implications for background and pseudo-absence data. Ecological Applications, 19(1): 181-197.

Pocock, M. J. O., Roy, H. E., Preston, C. D. \& Roy, D. B. (2015). The Biological Records Centre: a pioneer of citizen science. Biological Journal of the Linnean Society, 115(3): 475-493.

Pope, Addy. (2017). GB SRTM Digital Elevation Model (DEM) 90m, [Dataset]. EDINA. https://doi.org/10.7488/ds/1928.

Powney, G. D. \& Isaac, N. J. (2015). Beyond maps: a review of the applications of biological records. Biological Journal of the Linnean Society, 115(3), 532-542.

Prendergast, J. R., Wood, S. N., Lawton, J. H. \& Eversham, B. C. (1993). Correcting for variation in recording effort in analyses of diversity hotspots. Biodiversity Letters, 1(2): $39-53$.

Razgour, O., Hanmer, J. \& Jones, G. (2011). Using multi-scale modelling to predict habitat suitability for species of conservation concern: the grey long-eared bat as a case study. Biological Conservation, 144(12): 2922-2930.

R Core Team. (2018). R: A language and environment for statistical computing. $R$ foundation for Statistical Computing, Vienna, Austria. URL http://www.R-project.org/ .

Reeve, N. J. (1981). A field study of the hedgehog (Erinaceus europaeus) with reference to movements and behaviour. Ph.D. Thesis, University of London.

Reeve, N. J. (1994). Hedgehogs. London: T \& AD Poyser.

Rondinini, C., \& Doncaster, C. (2002). Roads as barriers to movement for hedgehogs. Functional Ecology, 16(4): 504-509.

Roos, S., Johnston, A., \& Noble, D. (2012). UK hedgehog datasets and their potential for longterm monitoring. Retrieved from BTO Research Report: https://www.bto.org/sites/default/files/u12/hedgehogscopingreportfinal05042012ptes.pdf

RStudio Team. (2018). RStudio: Integrated Development Environment for R Boston, MA. URL http://www.rstudio.com/.

Rytwinski, T. and Fahrig, L. (2015). The impacts of roads and traffic on terrestrial animal populations. In handbook of road ecology (eds R. van der Ree, D. J. Smith and C. Grilo). doi:10.1002/9781118568170.ch28

Rytwinski, T., Soanes, K., Jaeger, J. A., Fahrig, L., Findlay, C. S., Houlahan, J., van der Ree, R. $\&$ van der Grift, E. A. (2016). How effective is road mitigation at reducing road-kill? a meta-analysis. PLoS ONE, 11(11): e0166941.

Santos, S. M., Lourenco, R., Mira, A. \& Beja, P. (2013). Relative effects of road risk, habitat suitability, and connectivity on wildlife roadkills: the case of tawny owls (Strix aluco). PLoS ONE, 8(11): e79967.

Santos, R. A., Mota-Ferreira, M., Aguiar, L. M., \& Ascensão, F. (2018). Predicting wildlife roadcrossing probability from roadkill data using occupancy-detection models. Science of the Total Environment, 642: 629-637.

Scholefield, P. A; Morton, R D; Rowland, C S; Henrys, P A; Howard, D C \& Norton, L R. (2016). Woody linear features framework, Great Britain v.1.0. NERC Environmental Information Data Centre. https://doi.org/10.5285/d7da6cb9-104b-4dbc-b709$\underline{\mathrm{c} 1 \mathrm{f} 7 \mathrm{ba} 94 \mathrm{fb} 16}$ 
629

630

631

632

633

634

635

636

637

638

639

640

641

642

643

644

645

646

647

648

649

650

651

652

653

654

655

656

657

658

659

660

661

662

663

664

665

666

667
Schwartz, A. L. W., Williams, H. F., Chadwick, E., Thomas, R. J. \& Perkins, S. E. (2018). Roadkill scavenging behaviour in an urban environment. Journal of Urban Ecology, 4(1): $1-7$.

Silvertown, J. (2009). A new dawn for citizen science. Trends in Ecology and Evolution, 24(9): 467-471.

Slater, F. M. (2002). An assessment of wildlife road casualties - the potential discrepancy between numbers counted and numbers killed. Web Ecology, 3: 33-42.

UK-Gov. (2018). Road traffic forecasts: moving Britain ahead. Retrieved from https://assets.publishing.service.gov.uk/government/uploads/system/uploads/attachment data/file/740399/road-traffic-forecasts-2018.pdf

van der Ree, R., Jaeger, J. A., van der Grift, E., \& Clevenger, A. (2011). Effects of roads and traffic on wildlife populations and landscape function: road ecology is moving toward larger scales. Ecology and Society, 16(1): 48.

van Strien, A. J., van Swaay, C. A. M. \& Termaat, T. (2013). Opportunistic citizen science data of animal species produce reliable estimates of distribution trends if analysed with occupancy models. Journal of Applied Ecology, 50(6), 1450-1458.

van Vuurde, M. R., \& van der Grift, E. A. (2005). The effects of landscape attributes on the use of small wildlife underpasses by weasel (Mustela nivalis) and stoat (Mustela erminea). Lutra, 48(2): 91.

Vercayie, D. \& Herremans, M. (2015). Citizen science and smartphones take roadkill monitoring to the next level. Nature Conservation, 11: 29-40.

Vincent Wildlife Trust (2019). [Range expansion of Mustela pitorius and Martes martes].

Waller, J. S., \& Servheen, C. (2005). Effects of transportation infrastructure on grizzly bears in northwestern Montana. The Journal of Wildlife Management, 69(3): 985-1000.

Wembridge, D. E., Newman, M. R., Bright, P. W., \& Morris, P., A. (2016). An estimate of the annual number of hedgehog (Erinaceus europaeus) road casualties in Great Britain. Mammal Communications, 2: 8-14.

Williams, B. M., Baker, P. J., Thomas, E., Wilson, G., Judge, J., \& Yarnell, R. W. (2018). Reduced occupancy of hedgehogs (Erinaceus europaeus) in rural England and Wales: the influence of habitat and an asymmetric intra-guild predator. Scientific Reports, 8(1): 12156.

Williams, S. T., Collinson, W., Patterson-Abrolat, C., Marneweck, D. G., \& Swanepoel, L. H. (2019). Using road patrol data to identify factors associated with carnivore roadkill counts. PeerJ, 7: e6650.

Wood, S., \& Wood, M. S. (2015). Package 'mgcv'. R package version: 1-7.

Zuur, A. F., Ieno, E. N., \& Elphick, C. S. (2010). A protocol for data exploration to avoid common statistical problems. Methods in Ecology and Evolution, 1(1): 3-14. 
Figure 1

Location of the hedgehog roadkill presence data used for the sequential multi-level Habitat Suitability Modelling (HSM).

(A) the national scale model. (B) Major roads. (C) B-roads. (D) Minor roads. (E) All roads.
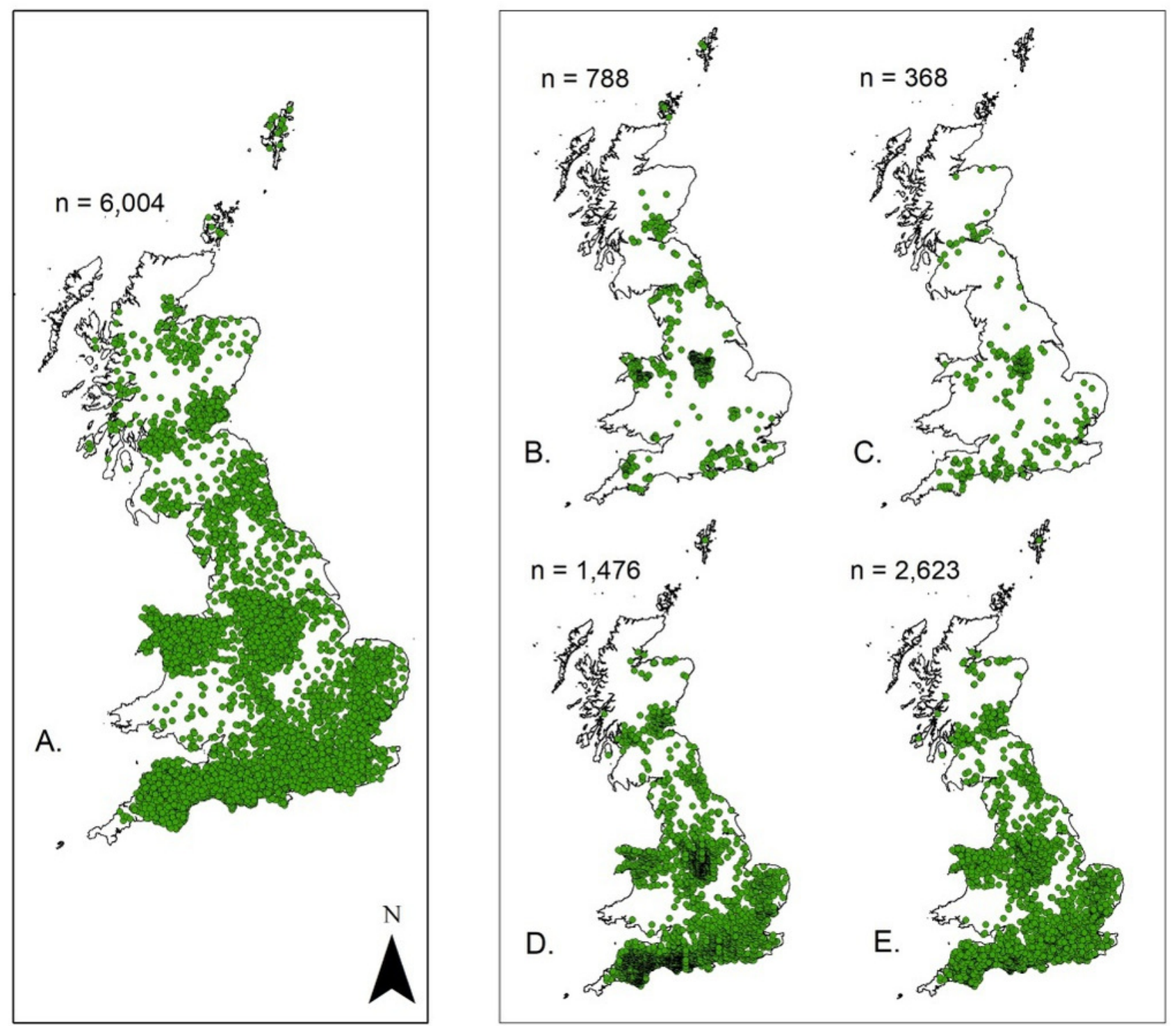
Figure 2

Seasonal variations in the number of hedgehog roadkill using a smoothing function (S) obtained by a generalized additive model (GAM). 


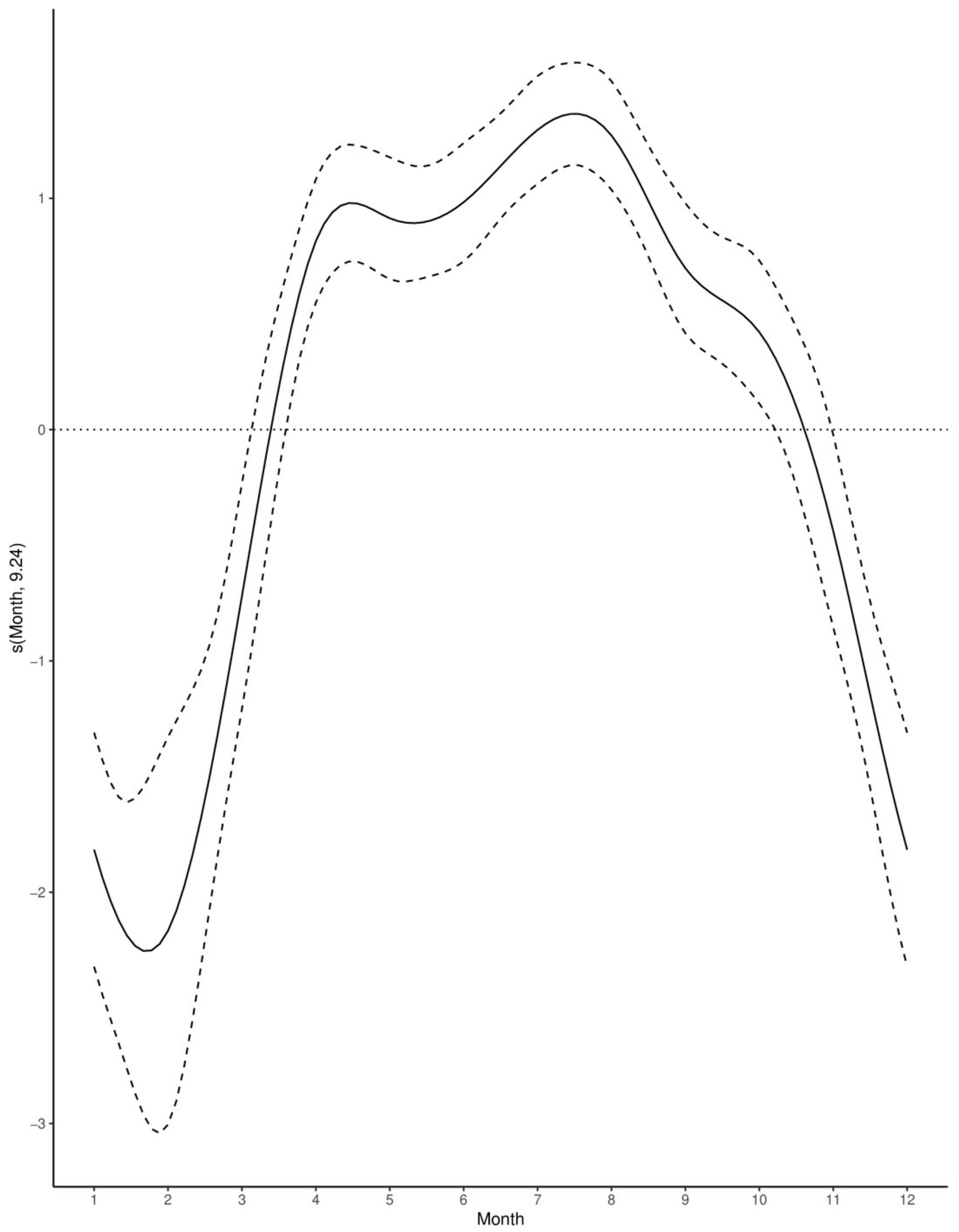


Figure 3

Mapped logistic habitat suitability indices (HSI) for E. europaeus roadkill at a countrywide level and road level using all roads.

Mapped logistic habitat suitability indices (HSI) for E. europaeus roadkill at a national level (A), and road level using all road data (B) according to the hierarchical, multi-scale model using roadkill background data. The response curves with the highest permutation importance are represented for the countrywide level (C), (D), (E) \& (F) and the model using all road data $(G),(H),(I) \&(J)$.
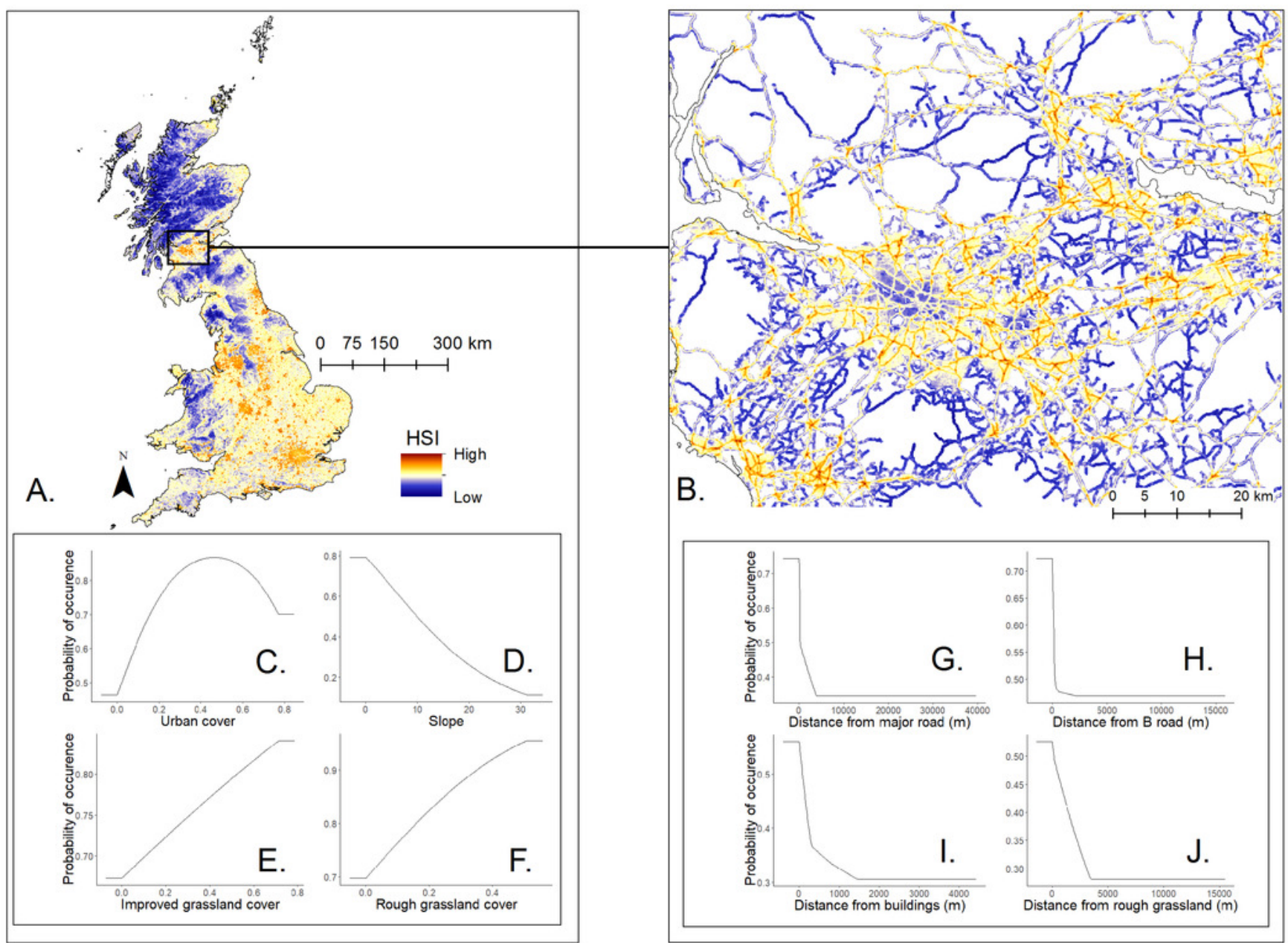
Figure 4

Binary output of logistic habitat suitability indices (HSI) for E. europaeus roadkill using all road data.

Red indicates areas with high probability of hedgehog roadkill occurrence and grey lines indicate all roads.

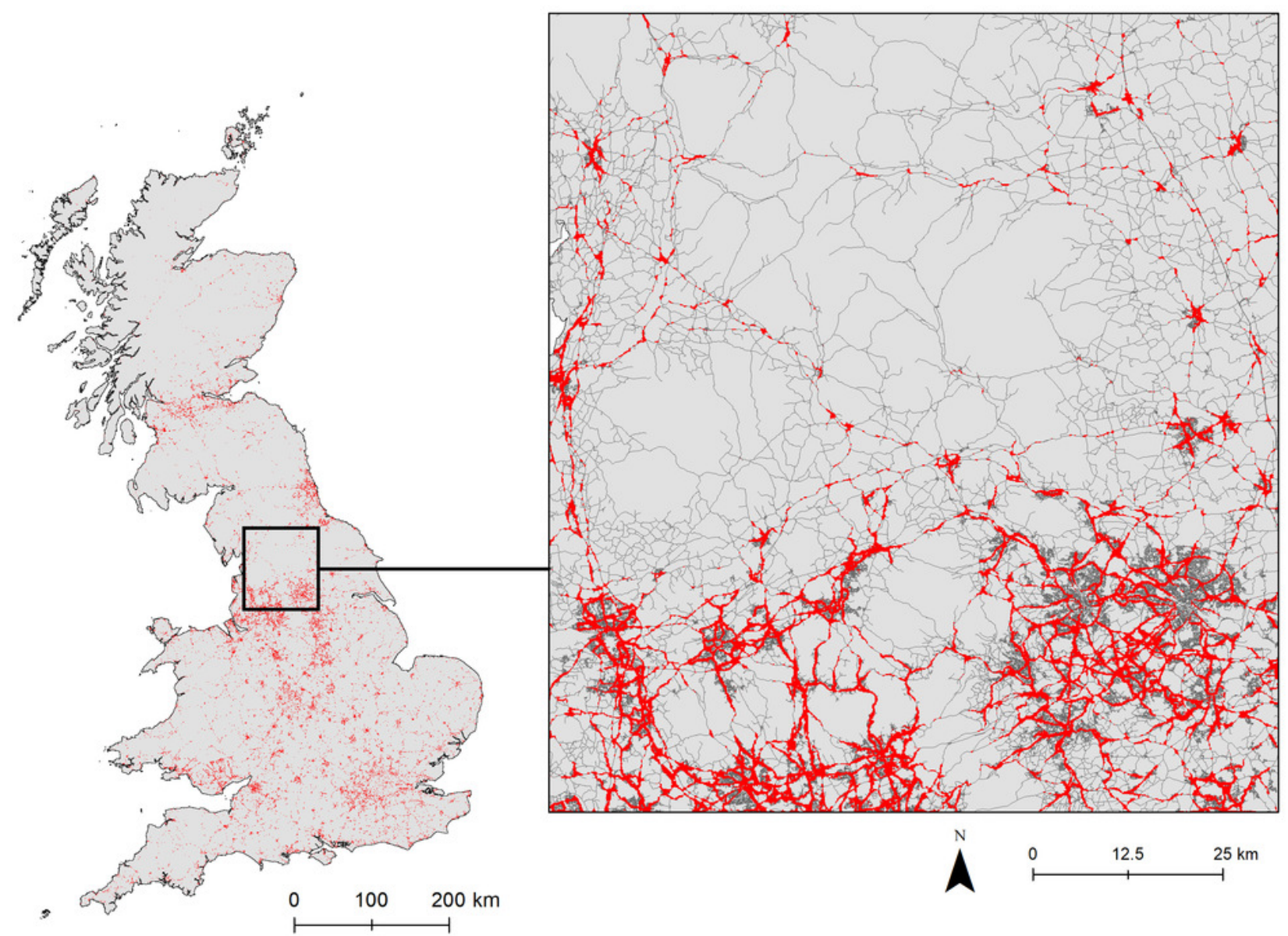


Figure 5

Map representing the correlation between the roadkill presence data and HSM model predictions.

(A) Persistence of records in $10 \mathrm{~km}$ grid cells since 2000. (B) Kernel density of roadkill records since 2000.

(C) Density of cells predicted as having a high probability of hedgehog roadkill occurrence (binary outputs) from the all road model.

The Pearson correlation between each map is indicated by the arrows.
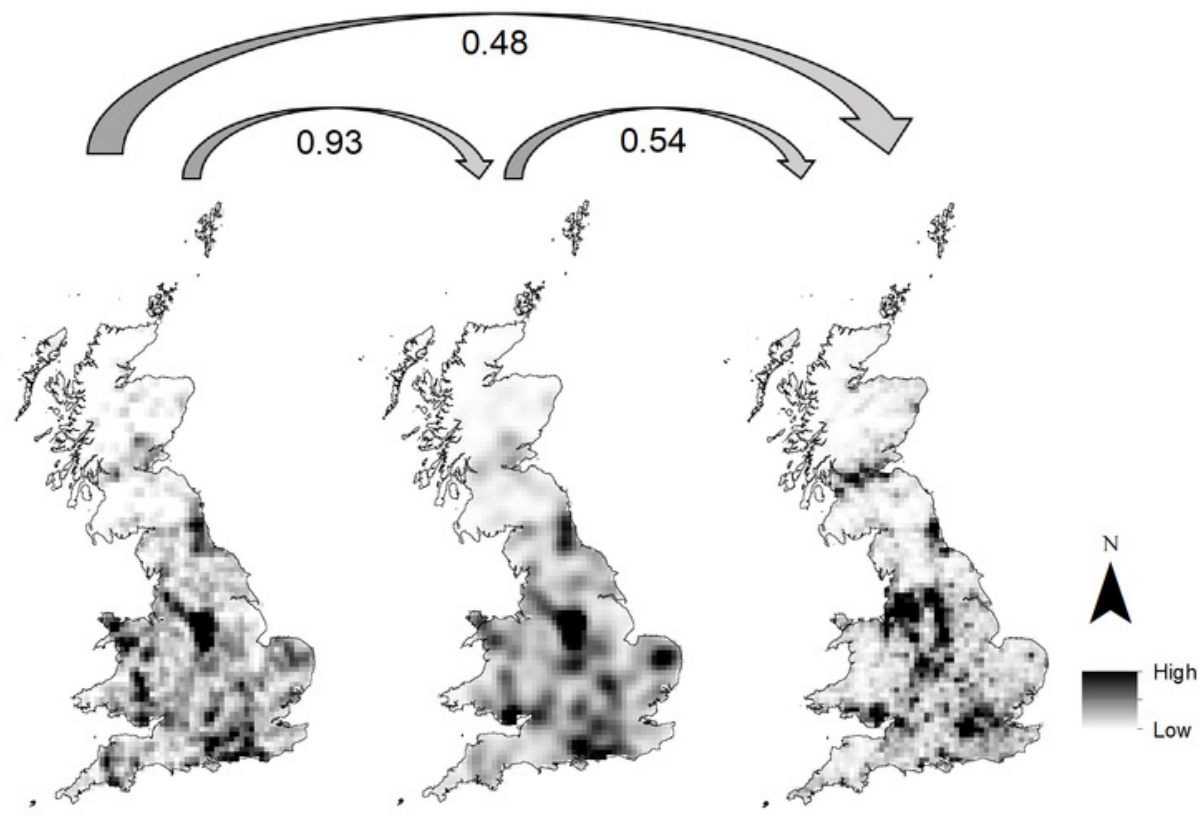

A. Persistence of records

B. Density of presence data

C. Density of binary outputs 


\section{Table $\mathbf{1}$ (on next page)}

Model performance of the final national scale $(1 \mathrm{~km})$ roadkill HSM using roadkill background data and the road HSM's (100 m).

Schoener's $\mathrm{D}$ index scores represent the niche overlap between models using random and roadkill background data. 


\begin{tabular}{|c|c|c|}
\hline Explanatory variable & Resolution & Source \\
\hline Arable $(\%$ cover $)$ & $1-3 \mathrm{~km}$ & Land Cover 2007 (LCM: Morton et al., 2011) \\
\hline Broadleaved $(\%$ cover $)$ & $1-3 \mathrm{~km}$ & Land Cover 2007 (LCM: Morton et al., 2011) \\
\hline Coniferous woodland ( $\%$ cover $)$ & $1-3 \mathrm{~km}$ & Land Cover 2007 (LCM: Morton et al., 2011) \\
\hline Urban $(\%$ cover $)$ & $1-3 \mathrm{~km}$ & Land Cover 2007 (LCM: Morton et al., 2011) \\
\hline Improved grassland (\% cover) & $1-3 \mathrm{~km}$ & Land Cover 2007 (LCM: Morton et al., 2011) \\
\hline Rough grassland (\% cover) & $1-3 \mathrm{~km}$ & Land Cover 2007 (LCM: Morton et al., 2011) \\
\hline Freshwater $(\%$ cover $)$ & $1-3 \mathrm{~km}$ & Land Cover 2007 (LCM: Morton et al., 2011) \\
\hline Greenspace ( $\%$ cover $)$ & $1-3 \mathrm{~km}$ & OS MasterMap Topography Layer (2019) \\
\hline Hedgerow density & $1-3 \mathrm{~km}$ & Woody Linear Features (Scholefield et al. 2016) \\
\hline Slope & $1-3 \mathrm{~km}$ & SRTM Slope DEM (Pope, 2017) \\
\hline All road traffic & $1-3 \mathrm{~km}$ & data.gov.uk (2019) \\
\hline B road density & $1-3 \mathrm{~km}$ & OS Open Roads (2019) \\
\hline Major road density & $1-3 \mathrm{~km}$ & OS Open Roads (2019) \\
\hline Major road traffic & $1-3 \mathrm{~km}$ & data.gov.uk (2019) \\
\hline Minor road density & $1-3 \mathrm{~km}$ & OS Open Roads (2019) \\
\hline Minor road traffic & $1-3 \mathrm{~km}$ & data.gov.uk (2019) \\
\hline Population density & $1-3 \mathrm{~km}$ & EEA (Gallego, 2010) \\
\hline Summer precipitation & $1-3 \mathrm{~km}$ & WorldClim - Global Climate Data (Fick \& Hijmans, 2017) \\
\hline Summer temperature & $1-3 \mathrm{~km}$ & WorldClim - Global Climate Data (Fick \& Hijmans, 2017) \\
\hline Distance from arable $(\mathrm{m})$ & $100-500 \mathrm{~m}$ & Land Cover 2007 (LCM: Morton et al., 2011) \\
\hline Distance from broadleaved woodland $(\mathrm{m})$ & $100-500 \mathrm{~m}$ & Land Cover 2007 (LCM: Morton et al., 2011) \\
\hline Distance from Greenspace $(\mathrm{m})$ & $100-500 \mathrm{~m}$ & Land Cover 2007 (LCM: Morton et al., 2011) \\
\hline Distance from buildings (m) & $100-500 \mathrm{~m}$ & Land Cover 2007 (LCM: Morton et al., 2011) \\
\hline Distance from improved grassland (m) & $100-500 \mathrm{~m}$ & Land Cover 2007 (LCM: Morton et al., 2011) \\
\hline Distance from urban area $(\mathrm{m})$ & $100-500 \mathrm{~m}$ & Land Cover 2007 (LCM: Morton et al., 2011) \\
\hline Distance from suburban area $(\mathrm{m})$ & $100-500 \mathrm{~m}$ & Land Cover 2007 (LCM: Morton et al., 2011) \\
\hline Distance from major road* & $100-500 \mathrm{~m}$ & OS Open Roads (2019) \\
\hline Distance from B-road* & $100-500 \mathrm{~m}$ & OS Open Roads (2019) \\
\hline Distance from minor road* & $100-500 \mathrm{~m}$ & OS Open Roads (2019) \\
\hline
\end{tabular}


Slope

$100-500 \mathrm{~m} \quad$ SRTM Slope DEM (Pope, 2017)

HSM (1-3 km)

$100-500 \mathrm{~m}$

- 


\section{Table 2 (on next page)}

Model performance of the final national scale $(1-3 \mathrm{~km})$ and the road $(100-500 \mathrm{~m})$ roadkill HSMs using roadkill background data.

Schoener's $D$ index scores represent the niche overlap between models using random and roadkill background data. 
1

\begin{tabular}{lcccccc}
\hline \multicolumn{1}{c}{ Model type } & $\mathrm{N}$ & $\begin{array}{c}\text { Feature } \\
\text { types }\end{array}$ & $\begin{array}{c}\text { Regularisation } \\
\text { multiplier }\end{array}$ & AICc & $\begin{array}{c}\text { Full } \\
\text { AUC }\end{array}$ & $\begin{array}{c}\text { Schoener's } \\
\text { D }\end{array}$ \\
\hline \hline National $(1 \mathrm{~km})$ & 6,004 & LQ & 1 & 138,246 & 0.72 & 0.85 \\
\hline Major road $(100 \mathrm{~m})$ & 788 & LQ & 1 & 22,054 & 0.5 & 0.9 \\
B road $(100 \mathrm{~m})$ & 368 & LQH & 4 & 10,186 & 0.6 & 0.84 \\
Minor road $(100 \mathrm{~m})$ & 1,476 & LQH & 4 & 44,442 & 0.71 & 0.93 \\
All roads $(100 \mathrm{~m})$ & 2,623 & LQHPT & 4 & 79,724 & 0.74 & 0.92 \\
\hline
\end{tabular}

